\title{
The Emotional Climate Scale: Understanding Emotions, Context and Justice
}

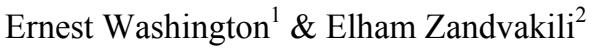 \\ ${ }^{1}$ Professor, Emeritus, Department of Teacher Education \& Curriculum Studies, University of Massachusetts, \\ Amherst, USA \\ ${ }^{2} \mathrm{PhD}$ Candidate, Language Literature and Culture in the College of Education, University of Massachusetts, \\ Amherst, USA \\ Correspondence: Elham Zandvakili, PhD Candidate, Language Literature and Culture in the College of \\ Education, University of Massachusetts, Amherst, USA. E-mail: ezandvakili@umass.edu
}

Received: October 15, 2018

Accepted: November 20, 2018

Online Published: December 30, 2018

doi:10.5539/jel.v8n1p21

URL: https://doi.org/10.5539/jel.v8n1p21

\begin{abstract}
The Emotional Climate Scale (ECS) was used to study the emotional responses of minority and majority elementary school students to different settings within their schools. The ECS applies a 7 point Likert scale to assess the emotions of anger, sadness, anxiety, loneliness, calmness, excitement, happiness, and hope in the school settings of the school bus, the playground, the principal office as well as the English, mathematics, social studies, and science classes. Minority children are significantly happier and lonelier on the bus and they are also more excited, angry and lonely in English classes than their white peers. In math classes minority children are more excited but lonelier. On the playground minority children are significantly sadder than majority children. In the principal's office, minority children are significantly calmer than majority children. In science, minority children were significantly more excited and hopeful. In social studies minority children were also more excited. In the gym, there were no significant differences between majority and minority children. Excitement and happiness are the two positive emotions are preferred and appropriate for all classes. A key question raised by the ECS is the question "Is this school fair to minority children?" The presence of loneliness, sadness, and anger are troubling indicators of something that is not right in this school.
\end{abstract}

Keywords: emotional climate scale, anger, sadness, anxiety, loneliness, calmness, excitement, happiness, hope

\section{Introduction}

\subsection{The Emotional Climate Scale}

This study of the Emotional Climate Scale (ESC) compares majority and minority children across the different settings in an elementary school. The emotions included in the scale are: anger, sadness, anxiety, loneliness, happiness, calmness, excitement and they are indicators of the social relations within schools. When these emotions are negative, these are indicative of injustice. Justice is not a set of abstract principles but emotional reactions to be cultivated, supported and taught. A sense of justice describes a social and emotional relationship (Solomon, 1995). Emotions are the bases of our sense of justice and the cornerstone of moral development (Kagan, 1984). For Kagan, morality is based upon emotional development which he argues are universal. Children learn certain key emotions in a developmental and predictive manner. By the time the child is three years old, she has developed standards of right and wrong, good and bad. Children of four years react with anger at the interruption of a purposeful activity, frustration of a motive, seizure or loss of an object. Anger and its display signals to other that this child will resist unfair treatment. At four, the child also experiences guilt. By six or seven, most children are capable of setting standards for abilities, attractiveness, honesty, bravery, dominance, and popularity.

A full description of emotions includes an image, cognition, a judgement, a physiological reaction and a goal. A cognitive statement of appraisal is used here in place of a fuller description. The ECS assumes that emotions indicate how children feel about and appraise their schools. The patterns of emotions tell us whether children think that their schools are just and fair. The ECS yields a profile of emotions, which can be interpreted as statements about the social world. There is a social logic to emotions because emotions evolved to structure 
relations within the group and promote the welfare of the group.

\subsection{Justice}

Justice is a blend of emotions. Our sense of justice is a reflection of our positive and negative emotional experiences. Caring is the most basic of the emotions because if we did not care, there would be no emotions. Justice begins with caring as well as the positive and negative emotions. We learn about emotions by being engaged in the world in which we have positive and negative experiences. Negative emotions are the reactions to the hurts experienced by ourselves and others for whom we care. There are complementary relations between positive and negative emotions (Solomon, 1959). It should also be acknowledged that the more we care for another person, the more likely we are to react with strong and negative emotions when that person is harmed or threatened. Justice is a blend of the positive emotions of caring, calmness, happiness, excitement and the negative emotions of anger, fear, anxiety, and sadness. The ECS yields a profile of the ratings of emotions by children of their reactions to the different settings in their educational environment. The idea behind the ESC is the common place experience that, "I feel angry/happy/calm/anxious when I am in math", and I feel happy/excited/calm in science class. In other words, we have different emotional reactions to the different settings within the school. Emotions are sensitive indicators of social relations of schooling because they have truth-value, they reach out to the world and inform us about how children experience the different settings in their school.

\subsection{School Context}

Schools consist of not one but many different social settings, and these settings are formal and informal in their social organization. In the formal structure of the school professionals take the responsibility for specifying the rules and structure of social relationships. The formal settings of the school include the classrooms and the principal's office. In the informal settings, the children set the rules and structure the relationships between students. The playground and the buses are two settings within the educational purview of the school that are free of formal supervision. These settings are places where children can and do choose to be with their friends, set their own rules, and to create a social structure.

The ECS belongs to a tradition of school climate studies: Haynes, Emmons and Ben-Avie (1997), Tarter, Sabo and Hoy (1995) and Johnson W., Johnson A., Ryan and Eden (1995). School climate studies usually include multiple subscales such as: teacher-student relationships, security and maintenance, administration, student academic orientation, student values, student-peer relationships, parent and community-school relationships and instructional management. There are also often multiple forms that address the perceptions of teachers, parents and students.

The ECS is a helpful addition to the study of the ecology of schooling because emotions are a critical dimension of human relationships and schooling (Oatley \& Nundy, 1996). In addition, Parrott and Harre (1996) and Taylor (1996) argue that emotions are instruments of social control and help regulate superordinate relationships. Emotions tell us about social relationships, and have a role in the coordination of social action. The use of the language of emotions rests upon a shared acceptance of the cultural rules that guide emotions. The statements, "I love you and/or I hate you", rest upon the assumption that the speaker and the object of the emotions understand the rules that constitute the specific emotion. It is the agreement about the rules and conduct of emotions that is the basis for social regulations.

\section{Review of the Literature}

\subsection{Theories of Emotions}

Research over the last several decades has demonstrated that the line between emotion and thought is more complex than was first apparent. Three research strategies have emerged to account for this newfound complexity. These strategies are the dual information processing approach, the cognitive appraisal strategy and the social constructionist view. The dual systems approach conceives of emotions as having some non-cognitive origin that may or may not subsequently lead to cognitive activity. The cognitive appraisal approach considers emotion as necessarily involving an appraisal of the situation, which may or may not be biased. A third perspective, the social constructivist approach is a rather broad-based approach, which is exemplified in the work of Averill (1994) and Harre and Gillett (1994).

Emotions are forms of judgment, ways of experiencing and engaging in the world. They are conceptual structures, casting others and ourselves in dramatic scenarios in which things matter. It is not just that in our emotions we recognize our relationships; it is through our emotions that we constitute them. More than we willingly recognize, we are creatures of emotions (Solomon, 1995). 
Emotions are processed by an experiential system that processes affective experiences through associative processes. Behavior is mediated by "feeling and vibes" from past experiences and encoded in concrete images, symbols and narratives. Information is processed in a rapid fashion oriented toward action; change is slower, though change does occur with repetition and intense experiences. This system is integrated with emotions and context specific processing that is experienced passively, pre-consciously and consciously.

Harre and Gillett (1994) describe their approach to emotions as discursive that includes four major facets. 1) Emotions are the psychological equivalent of statements, 2) Emotions depend upon a shared language and a common background of knowledge and belief, 3) Emotions includes social displays in particular circumstances, 4) Feelings and displays are components of emotions and they accomplish two things a) They are embodied in expressions of judgments and emotions are ways of accomplishing certain acts. For example, a display of anger expresses a judgement of the moral quality of some other person's actions. Emotions, feelings and displays are expressions of judgments, which lack premises. Judgments rest on a biological response and cultural training. In short, for Harre and Gillett, emotions are judgments within a moral order. Gillett and Harre propose that emotions can express one or more of the following kinds of judgments: 1) A moral 0-pjudgment that the action of another is a transgression or a prosocial action that can be expressed in a social display, 2) They are aesthetic judgments that certain reactions are appropriate to a given situation, and 3) There are prudential judgments that display a warning.

Justice is a complex set of passions to be developed and cultivated. The passion to be cultivated should include: the sympathetic emotions of caring, happiness, excitement, hope, and calmness. According to Solomon (1995) caring is not an emotion to be taken lightly because human beings fight over things they care about. The unsympathetic emotions of envy, jealousy, anger and resentment are important landmarks because Solomon argues that the sympathetic emotions stand not in opposition to each other but as supports.

\subsection{Emotions in Schools: The Experiences of Minority Children}

Schools operate on the premise that children belong to an educational community which is just and fair. This underlying assumption is fundamental to the continued functioning and acceptance of schools. This is the working assumption of schools as they struggle with the education of minority and majority children. Over the past several decades there have been persistent efforts to educate minority children to the same standards as those achieved by majority students. These efforts have not been successful. The persistent failure of minority children has become a matter of national concern and debate. There have been many approaches to identifying the influences which create failure among minority students. Some of the explanations for the continued failure of minority youngsters are described below.

Ogbu $(1987,1989)$ lodges the explanation of school failure in a caste system in which minority youngsters are socialized into minority group status. Trueba (1989) and other ethno-methodologists find the genesis of school failure in conflicts between the home and the school. Judith Rich Harris (1998), in her provocative book, "The Nurture Assumption: Why children turn out the way they do; Parents matter less than you think and peers matter more", provides an interesting explanation of the failure of minority children. She lodged the educational difficulties of minority children within the peer group culture. It is her view that minority children want to be like their peers rather than their parents, and peers emulate others who are not educationally successful. She argues that when minority children have high achieving peer groups they are educationally successful.

According to Harris, peer groups facilitate the stratification of children. From the kindergarten years through second grade, the influence of the teacher is sufficiently strong to counter the influence of peer groups. The later elementary school years mark the increasing influence of peer groups and the social stratification within the elementary school years. It is at this point that the precipitous downward slide of achievement by minority youngsters helps peer groups orchestrate their power and influence.

It is helpful to note that these different approaches taken toward the analyses of school failure by minority children are not in conflict with each other. It is indeed possible that Ogbu (1989) is correct that a caste status is detrimental to achievement, Trueba might also be correct that there are conflicts between school and home that limit the achievement of children, and Judith Harris may also be partially correct in that peers do matter. Solomon (1995) would argue that schools fail minority children because they are unjust and children recognize and learn to accept the hidden messages that blame them for their failure.

\subsection{Eight Emotions of the Emotional Climate Scale}

This brief discussion of the emotions the ECS includes negative and positive emotions. The negative emotions are: anger, sadness, anxiety and loneliness while the positive emotions are: calmness, excitement, happiness and 
hope. Each share the five dimensions of: an image, a bodily feeling, a social display, a moral/evaluative dimension that can be readily identified and a goal.

Anger. Harre and Gillett (1994) begin their discussions of anger with a reference to Sterns and Sterns (1988) who traced the historical uses of the word, anger. They found that early English speakers in Massachusetts during the seventeenth century did not include descriptions of private bodily feelings but did emphasize public display. Anger includes the components of a proposition of being treated unfairly; there is an insult to self-esteem and dignity that is unjustified. There is usually a bodily arousal that reverberates from the amygdala to facilitate a fight reaction. Thoughts of retaliation follow with characteristic facial expressions, and a willingness to respond that is proportional to the initial arousal. Public displays of anger convey moral and prudential judgments. There is a clear statement that the individual has been treated wrongly, and a warning is sent out.

Sadness. Sadness makes a statement about a significant loss such as a major disappointment, loss or even in the extreme, a death. There is a crying; a loss of energy and enthusiasm while the body's metabolism slows. The individual gets the blues and is often introspective. The social display has a characteristic facial expression that includes a down turned mouth, half-closed eyes accompanied by drooping shoulders and a slumping posture. The moral statement is clearly one of a perceived irrevocable loss that has life changing potential.

Anxiety. Anxieties are characterized by subjective feelings of tension, apprehension, nervousness, worry, activation (arousal), and the discharge of the autonomic system. Anxiety varies in intensity and fluctuates over time as a function of the amount of stress. Anxiety is other directed, directed toward the world as a whole, it's object can be anything and everything, everything is a threat, causes defensiveness, distrust. The person experiencing anxiety can find worry at every turn and finds herself going to heights and wanting to disappear. It calls forth a sense of paranoia, selfishness, a lack of consideration for others while demanding their sympathy and accepting no responsibility.

Loneliness. Loneliness is synonymous with modernity, and a symptom of the isolation in a world without social connections. Human beings are social beings, and when social connections are not available, the emotion of loneliness is expressed. The image of being alone joins to feelings of isolation and separation, disappointment and anger followed by a search for closeness and intimacy of friendships.

Calmness. Calmness refers to a lack of agitation, tranquility, and serenity, at ease. Calmness is connected with the rational impulse for self-control of the positive and negative emotions. Calmness is an emotion that like other emotions can be conscious, unconscious, or slip between the two states of mind. Calmness is an important and moderating influence upon the positive and the negative emotions. Calmness has an image that is seen in facial expression, the thoughts of calmness pictures a face in the world, the cognitive expression of calmness is a rational impulse toward self-control and moderation, and the goal is the view that calmness contribution toward happiness and success.

Excitement. Excitement refers to the capacity to regulate and express the level of excitation. Excitement is necessary because if angry, it is possible to fight; if afraid he can run, if he is love, he can speak. There is an optimal level of excitation, which is pleasurable. Excitement is regulated through relations with significant others. Excitement is unique in that it is an emotion without a goal.

Happiness. Happiness is a statement of approval with regard to a significant event or events. The body enters a state of heightened anticipation of success, becomes more resilient and recovers earlier from insults. The social display of the face includes appropriate smiling, enthusiasm and an exhibition of energy. The moral statement is a judgment of approval of a recent life change.

Hope. Hope is a tendency to persuade oneself that what is desired will come to pass. The hope is undoubtedly a universal and even necessary part of life, but such emotions are probably related to optimism. Optimism and hope are sometimes treated as though they were nearly identical; however, it is easy to demonstrate their independence. For example, a person may be so pessimistic that nothing is left but hope (Averill, 1996). Hope is accompanied by images, feelings, judgments, but there is a gap between the likelihood of success and reality. Hope is connected to spirituality in many communities and the desire for that which is unlikely.

This is a study of the differences in responses of minority and majority children to the Emotional Climate Scale. The Emotional Climate Scale provides a profile of the ratings of emotions of children to the different parts of their educational environment. The emotions of hope, happiness, loneliness, calmness, anger, excitement, fear, loneliness and sadness are rated on a Likert scale of one to seven.

\subsection{Hypothesis and Research Questions}

In particular, it is hypothesized that patterns of emotions within informal and formal settings are a part of an 
on-going stratification process in which minority and majority youngsters have substantially different emotional experience in the different settings of the school. In the formal and informal settings of the playground minority children are lonelier, less hopeful and often unhappy and frequently sad. The mixtures of emotions are capable of creating and becoming instrumental in the cycles of underachievement by minority children.

The analysis of this preliminary data provides answers to a series of questions: 1) "Is this a reliable instrument?", "2) "Do minority children have an emotionally different educational experience from majority children in the different settings of the school?" 3) Is the school just and fair for minority youngsters?"

\section{Method and Procedure}

\subsection{Participants}

The sample consisted of eighty-three children of European-American backgrounds, two African-Americans, four Cambodian-Americans, two Korean-Americans and eight others from different ethnic backgrounds. The school was an elementary school located in a small community located near a University community.

\subsection{Questionnaire Instructions}

This is a study of the emotional climate of schools. You will evaluate classes and events by rating them on a seven-point scale. (1=low and 7=high). On each of the following pages are a title and a list of eight emotions each with seven dots. Read the tile and circle on the dot for each of the eight emotions. For example:

\begin{tabular}{lll}
\hline HOME WORK & \\
\hline & LOW & \\
1. EXCITED & & \\
2. SAD & & \\
\hline
\end{tabular}

This person rated \#1 Excited with a level of six and \#2 sad with a level of one. That means the last homework assignment this person completed. They experienced the homework with a high level of excitement and low level of sadness.

Do you have any questions? If you have no questions, please begin.

The experimenter responded to help those children who had questions about completing the scale.

\section{Results}

\subsection{Reliability}

The reliability of the entire scale was .91. The entire scale consisted of subscales for each of the eight emotions. Each of the eight emotions was applied to each of the eight settings. The subscale for anger for example appeared on each of the measures of eight settings. Therefore, there was an item for anger for the following settings: bus, English, gym, etc. The reliabilities for the subscales were as follows: anger .77 , calm .75 , excited .69, happy .77, hope .84, fear .76, lonely .76, and sad, 76 .

\subsection{Statistical Analysis}

Table 1 presents the Discriminant Analysis, F-Table that shows those settings/emotions in which there are significant differences between minority and majority children. The table includes: the variable, Wilks' Lambda (U-statistic) and univariate F-ratio with 1 and 96 degrees of freedom.

Table 1: Discriminant Analysis of Settings/Emotions

\begin{tabular}{llll}
\hline Variables & Wilks'Lambda (U-statistic) & F-ratio $(1,96)$ & P-Value \\
\hline Bus Lonely & 0.92 & 7.94 & .006 \\
Bus Happy & 0.92 & 8.34 & .004 \\
Eng Angry & 0.93 & 6.26 & .014 \\
Eng Excit & 0.94 & 6.12 & .01 \\
Eng Lonely & 0.86 & 15.54 & .000 \\
Playground Sad & .94 & 6.11 & .01 \\
Principal's office Calm & .99 & 6.20 & .01 \\
Science Excit & .95 & 4.85 & .02 \\
Science Hope & .96 & 3.1 & .07 \\
Social Excit & .94 & 5.28 & .02 \\
Math Excit & .94 & 5.26 & .02 \\
Math Happy & .93 & 6.69 & .01 \\
Math Lonely & .96 & 3.34 & .07 \\
\hline
\end{tabular}


The setting of the Bus shows that there are significant differences with regard to the emotions of happy, lambda $=.9201, \mathrm{~F}(1.96), \mathrm{F}=8.347, \mathrm{p}=.004$, and lonely lambda $=.9236, \mathrm{~F}(1.96), \mathrm{F}=7.942, \mathrm{P}=.006$. The differences between the two groups are highly significant.

The setting of the English class reveals differences in the emotions of anger, lambda $=.9388, \mathrm{~F}=6.2622, \mathrm{p}=$ 014 , excited, lambda $=.9400, \mathrm{~F}=6.120, \mathrm{p}=.015$ and loneliness, lambda $=.8607, \mathrm{~F}=.15 .541, \mathrm{p}=0002$.

The setting of the gym is a setting in which there are no differences between the minority and majority groups.

Math class brings forth significant differences with regard to excitement lambda $=.9481, \mathrm{~F}=5.260, \mathrm{p}=.02$, happiness lambda $=.9348, \mathrm{~F}=6.692, \mathrm{p}=.01$ and loneliness is marginally significant, lambda $=.9663, \mathrm{~F} \mathrm{~m}=$ $3.347, \mathrm{p}=.07$.

The emotion that separates minority and majority youngsters on the playground is sadness, Lambda $=.9401, \mathrm{~F}=$ $6.110, \mathrm{p}=.01$.

The principal's office produces significant differences between the two groups in the emotion of calmness, lambda $=.9997, \mathrm{~F}=6.209, \mathrm{p}=.01$.

There were significant differences between majority and minority youngsters on the emotion of excitement in science, lambda $=.9518, \mathrm{~F}=4.858, \mathrm{p}=.02$ while the emotion of hope was marginally significantly different, lambda $=.9678, \mathrm{~F}=3.189, \mathrm{p}=.0773$.

In the social studies class, there are significant differences in the state of excitement, lambda $=.9478, \mathrm{~F}=5.283$ and $\mathrm{p}=.02$.

\section{Discussion}

The data from this study show that The Emotional Climate Scale is a reliable instrument that reveals some interesting differences between majority and minority children in their ratings of the emotions in different settings in the school. The minority children were mostly bilingual youngsters whose families were recent immigrants. This study of ECS answers the three questions: 1) "Is this a reliable instrument?" 2) "Do majority and minority children respond differentially to various settings within the school?" 3 ) "Is the school just and fair for minority youngsters?"

The answers to questions one and two can be obtained from Table 1. From these data, we learn which emotions and settings are more positive and negative for the children. It will also be possible to look at the different settings within the school.

The experience of the bus was a very different experience for minority and majority children. The minority children were much lonelier than majority children. As most school administrators and teachers know, the bus is a source of much conflict and difference between children. The profile of the emotional climate scale shows that loneliness stands out as a consistent negative emotion, while among the positive emotions, children are also very happy. Interestingly, the minority youngsters rate their experiences as more positive than their majority youngsters.

The English class is a most problematic setting for minority youngsters because language is the subject matter. There were significant differences in loneliness, anger and excitement between minority and majority children. It is well to remember that many minority youngsters find learning English to be an activity that emphasizes the embarrassment of their differences. As a result, some feel lonely and angry. At the same time, they also feel the excitement of the challenge. The profile of emotions in the English class shows this class to be a time of uncertainty.

The gym is interesting because it is the only setting in the school in which there are no differences between minority and majority youngsters. Gym classes are carefully scripted by the teacher, and if there is a question about talent, it is physical talent.

In mathematics minority youngsters are significantly more excited, happy and lonelier than their white counterparts. Mathematics is a unique language in its own right, and the second language learners find mathematics to be a non-threatening social environment.

On the playground minority children were significantly sadder than majority children. The playground is one of those settings in the school where the children choose their playmates. It is not surprising that minority children are significantly sadder because they are chosen to play less often than majority children. The playground is a setting in which the children are free to write their own scripts and norms.

In science, minority youngsters are significantly more excited than their majority classmates. They also have 
significantly more hope. The combination of excitement and hope suggests that science is a very special time for this group of minority children. This same significant difference in the rating of excitement and hope were found for English and math.

The third question raised in this study was, "Is this school fair to minority children?". It is important to remember that emotions are a complex set of components that include: images, feelings, thoughts, judgments, and goals. The focus here is upon the judgments. Emotions are therefore a way of making judgments of right and wrong, Fairness or justice is defined here as a blend of the positive and the negative emotions. Unfairness is a pattern of negative emotions.

The data from this study revealed negative patterns of emotions that signal unfairness. One of the first and major findings of the study is how differently students experienced the different settings in the schools. The first negative pattern was the experiencing of loneliness by minority children on the bus and on the playground. These two settings are areas where students are able to set the norms for social and emotional relations.

A pattern emerged with regard to excitement. Minority youngsters were more excited in English, math, science and social studies. One possible interpretation of this finding is that excitement was close to happiness. An examination of the correlations between excitement, anger and happy indicated that excitement is more highly correlated with happiness than with anger.

The most interesting difference occurs between majority and minority students in English. This finding is not exceptional because the majority of these minority youngsters are children who have English as their second language. Very early in their lives these second language learners recognize that science is a place where they can have "hope". These youngsters are also excited about going to school. They are more excited than their counterparts in English and math.

The statistically significant pattern of heightened anger, excitement and loneliness in the English class is particularly worrying. English is the only class in which students judge themselves as being angry. When combined with the emotions of excitement and loneliness there is much room for misunderstanding. Anger is the sign of being unfairly treated. The patterns of loneliness are the other patterns of emotions in which there is unfairness. Discussions with minority youngsters indicate that they feel they are not being treated fairly by their peers. Informal discussions with the minority children indicate they are indeed lonely on the bus. Many school administrators report a range of conduct problems on the bus but the problems are more acute for minority youngsters. These youngsters report that majority children will not sit next to them on the bus. The pattern of children sitting with their friends often means minority children recognize that they are being excluded. Roughly the same pattern exists on the playground.

The voices of students are missing in this analysis of the settings of a school. According to Zandvakili (2012, 2013) ethnographical analyses of the social emotional identities of students will illuminate the dynamic passions that are the emotions. The Hymes' (1974) model of ethnography is a useful theoretical fit in understanding the responses of students across the different settings. Psychometric analyses of emotions have severe limitations and only the human narrative can reach beyond the limitations of numerical data. It is a human being who is experiencing the emotions of schooling.

\section{Conclusion}

This report compares majority and minority children using the Emotional Climate Scale. The scale measured the positive emotions of happiness, hope, excitement, and calmness on the positive side, and sadness, anger, fear, and loneliness. These emotions were rated across six different areas of an elementary school. the principal's office, English, science, math, and social studies as well as the bus and the playground. Minority children rated the bus and the playground as settings where they were lonely. English was the most challenging class for minority students who were significantly different from white students in the emotions of loneliness, excitement and angry. The minority youngsters experienced heightened excitement, loneliness but they were happy. The gym was the only setting in the school in which there were no differences between groups.

\section{References}

Delgado-Gaitan, C., \& Trueba, H. (1991). Crossing cultural borders: Education for immigrant families in America. Falmer Press, Taylor \& Francis Inc. https://doi.org/10.1525/aa.1993.95.1.02a00750

Epstein, S. (1994). Integration of the cognitive and the psychodynamic unconscious. American psychologist, 49(8), 709. https://doi.org/10.1037//0003-066x.49.8.709

Gibson, M. A., \& Ogbu, J. U. (1991). Minority status and schooling: A comparative study of immigrant and 
involuntary minorities. Garland Publishing, Inc. https://doi.org/10.1086/447358

Harré, R., \& Gillett, G. (1994). The discursive mind. Sage Publications. https://doi.org/10.1017/s0047404500018856

Harris, J. R. (2011). The nurture assumption: Why children turn out the way they do. Simon and Schuster. https://doi.org/10.2307/2654856

Haynes, N. M., Emmons, C., \& Ben-Avie, M. (1997). School climate as a factor in student adjustment and achievement. Journal of educational and psychological consultation, 8(3), 321-329. https://doi.org/10.1207/s1532768xjepc0803_4

Johnson, W. L. (1991). A Factorial and Rasch Analysis of the Charles F. Kettering Ltd. School Climate Profile. https://doi.org/10.2466/pr0.1990.67.1.67

Kagan, J. (1984). The nature of the child. Basic Books. https://doi.org/10.1016/0140-1750(85)90077-6

Lazarus, R. S., \& Lazarus, B. N. (1996). Passion and reason: Making sense of our emotions. Oxford University Press, USA. https://doi.org/10.5860/choice.32-4774

Oatley, K., \& Nundy, S. (1998). Rethinking the role of emotions in education. The handbook of education and human development: New models of learning, teaching and schooling, 247-262. https://doi.org/10.1111/b.9780631211860.1998.00013.x

Ogbu, J. U. (1979). Minority education and caste: The American system in cross-cultural perspective. Crisis, 86(1), 17-21. https://doi.org/10.2307/2064931

Parrott, W. G. (Ed.). (2001). Emotions in social psychology: Essential readings. Psychology Press.

Solomon, R. C. (1995). A passion for justice: Emotions and the origins of the social contract. Rowman \& Littlefield. https://doi.org/10.5860/choice.28-3263

Stearns, C. Z., \& Stearns, P. N. (1989). Anger: The struggle for emotional control in America's history. University of Chicago Press. https://doi.org/10.1017/s0033291700000945

Tarter, C. J. (1995). Middle School Climate, Faculty Trust, and Effectiveness: A Path Analysis. Journal of Research and development in Education, 29(1), 41-49.

Taylor, G. (1985). Pride, shame, and guilt: Emotions of self-assessment. https://doi.org/10.2307/2185420

Vaezi, S., Zand-Vakili, E., Mohammadkhani, A., \& Kashani, A. F. (2013). Emotional Intelligence and Beneficial Utilization of Teachers' Corrective Feedback (Recast and Elicitation): Investigating Possible Relations. World Applied Sciences Journal, 24(1), 64-75.

Von Wright, G. H. (2004). Explanation and understanding. Cornell University Press. https://doi.org/10.4324/9781315823171

Zand-Vakili, E., Kashani, A. F., \& Tabandeh, F. (2012). The Analysis of Speech Events and Hymes' SPEAKING Factors in the Comedy Television Series: "FRIENDS". New Media and Mass Communication, $2,27-43$.

\section{Copyrights}

Copyright for this article is retained by the author(s), with first publication rights granted to the journal.

This is an open-access article distributed under the terms and conditions of the Creative Commons Attribution license (http://creativecommons.org/licenses/by/4.0/). 